\title{
AROMATIC L-AMINO ACID DECARBOXYLASE ACTIVITY IN BRAINS FROM NORMAL HUMAN SUBJECTS AND FROM PATIENTS WITH EXTRAPYRAMIDAL DISEASES
}

\author{
MOHAMMED KHALILUR RAHMAN ${ }^{1 *}$, TOSHIHARU NAGATSU ${ }^{* * *}$, \\ IKUKO NAGATSU ${ }^{2}$, REIJI IIZUKA ${ }^{3}$ and HIROTARO NARABAYASHI ${ }^{4}$ \\ ${ }^{1}$ Laboratory of Cell Physiology, Department of Life Chemistry, Graduate School at Nagatsuta, Tokyo Insti- \\ tute of Technology, Yokohama 227, 2Department of Anatomy, School of Medicine, Fujita-Gakuen Uni- \\ versity, Toyoake, Aichi 470-11, and ${ }^{3}$ Department of Psychiatry and ${ }^{4}$ Department of Neurology, School of \\ Medicine, Juntendo University, Tokyo 113, Japan
}

\begin{abstract}
The activity of aromat.c L-amino acid decarboxylase (AADC) with L-DOPA and L-5-hydroxytryptophan (L-5-HTP) as substrates was measured in various regions of human brains from controls and patients with Parkinson's disease, striato-nigral degeneration, Shy-Drager syndrome, and perioral dyskinesia by our newly developed methods based on high-performance liquid chromatography with electrochemical detection. This is the first time that the distribution of L-5-HTP decarboxylase activity was measured in human brain regions. The activity and the ratio between the activity with L-DOPA and that with L-5-HTP were compared between different brain regions of the same subject and between the same brain regions from various patients.

In control brains, the hypothalamus, caudate nucleus, amygdala, and putamen had higher AADC activity for both L-DOPA and L-5-HTP as substrates, but comparatively low activity was observed in cerebral cortex and cerebellar cortex using both the substrates. The catecholaminergic regions of control brains such as the amygdala, hypothalamus, caudate nucleus, and putamen preferentially decarboxylated L-DOPA, whereas a serotonergic region such as the raphé nucleus had relatively high activity for L-5-HTP.

Both DOPA decarboxylase and 5-HTP decarboxylase activities and therefore, the ratio between the two kinds of activity were variable in the brains from controls and patients. The activity for both the substrates in the putamen of Parkinsonian patients was decreased, but in the amygdala of a patient we found even higher activity for L-5-HTP than in the controls. In the putamen of Shy-Drager syndrome the activity was very low and even undetectable for L-5-HTP in comparison with control brains.
\end{abstract}

These results tend to support the hypothesis of two types of AADC with different substrate specificity for L-DOPA and L-5-HTP in human brain.

KEY WORDS aromatic L-amino acid decarboxylase / high-performance liquid chromatography / dopamine / serotonin / human brains / Parkinsonism

\footnotetext{
* Visiting Research Fellow supported by the Japanese Government (Ministry of Education, Science and Culture) from the Department of Biochemistry, University of Rajshahi, Bangladesh ** To whom correspondence and reprint requests should be addressed. Abbreviations: AADC, aromatic Lamino acid decarboxylase; DA, dopamine; DHBA, dihydroxybenzylamine; 5-HT, 5-hydroxytryptamine; 5-HTP, 5-hydroxytryptophan; HPLC, high-performance liquid chromatography
} 
Aromatic L-amino acid decarboxylase (AADC) decarboxylates both L-DOPA and L-5-hydroxytryptophan (L-5-HTP) to produce dopamine (DA) and 5-hydroxytryptamine (5-HT), respectively $(1,5)$. The enzyme is responsible for the biosynthesis of catecholamines, (DA, noradrenaline and adrenaline) and indoleamines (5-HT and melatonin).

DOPA decarboxylase activity in human brain is very low and variable as compared with other animal species (14). In patients with Parkinson's disease, the concentration of DA in the nigro-striato-pallidal complex of the brain is generally decreased (2), and this reduction in DA could be due to reduction of the enzymes of DA biosynthesis. It was reported that the activity of DOPA decarboxylase in the striatum of patients with Parkinsonism was greatly reduced (3). Nagatsu et al. (6-9) reported that, although tyrosine hydroxylase activity and the biopterin cofactor level were greatly reduced in Parkinsonian striatum, DOPA decarboxylase activity was variable, low in many cases, but normal, or even high in some cases.

AADC with 5-HTP as substrate in human brain could be detected with isotopes (4) but was reported to be even lower than that with LDOPA as substrate $(4,15)$, and no precise data on regional distribution of 5-HTP decarboxylase activity was available for controls and patients, because of its very low activity and the unavailability of a sensitive method.

We have already developed very sensitive methods for the measurement of the activity of L-DOPA decarboxylase (10) and L-5-HTP decarboxylase (11) using high-performance liquid chromatography with electrochemical detection (HPLC-ED), and applied our methods for the measurements of AADC activity in rat brains and tissues using as substrates both L-DOPA and L-5-HTP (12) and in various animal sera (13).

In the present study we have applied our new method to the assay of L-DOPA decarboxylase and L-5-HTP decarboxylase activities in human brain regions from controls and patients with Parkinson's disease, striato-nigral degeneration, Shy-Drager syndrome, and perioral dyskinesia.

\section{MATERIALS AND METHODS}

\section{Human Brains}

The case histories of the patients are shown in Table 1. The control human brains and the brains from patients with Parkinson's disease, striato-nigral degeneration, Shy-Drager syndrome and perioral dyskinesia were obtained at autopsy. The brains were removed between 1 and $9 \mathrm{hr}$ postmortem, immediately frozen and stored at $-80^{\circ} \mathrm{C}$. None of the control patients had a history of neurological disorders, nor were

Table 1 Case Histories of Controls and Patients

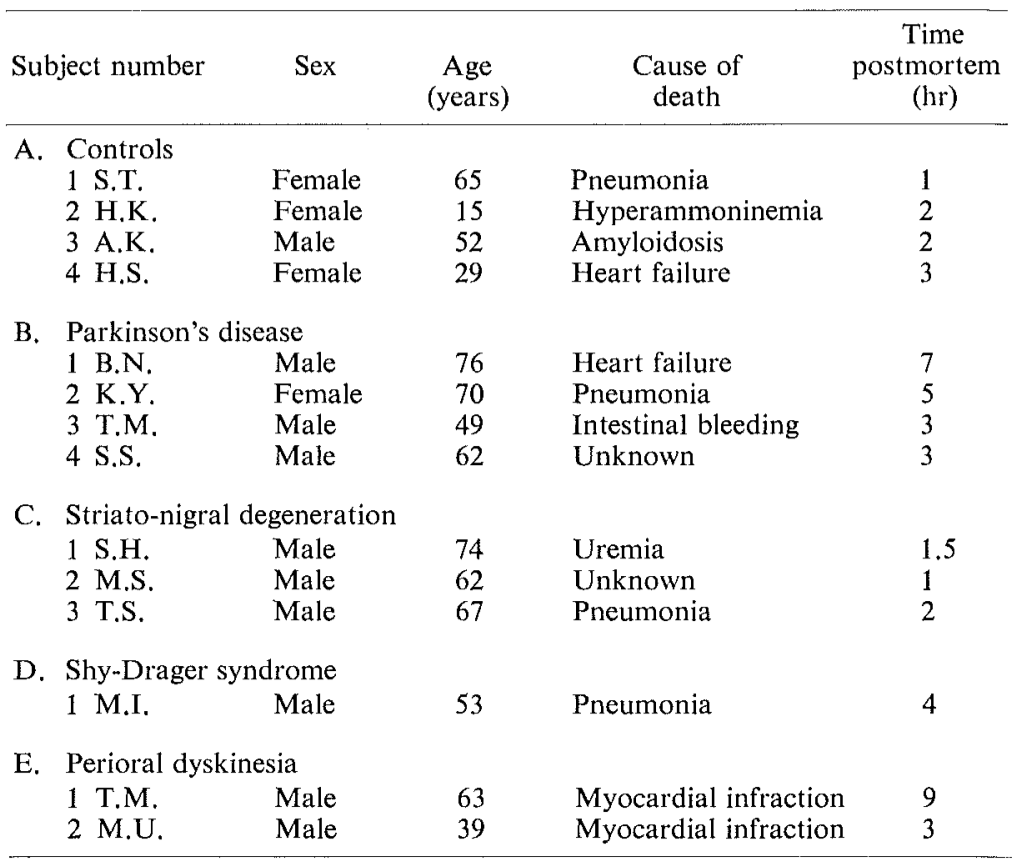




\section{(A) Control}

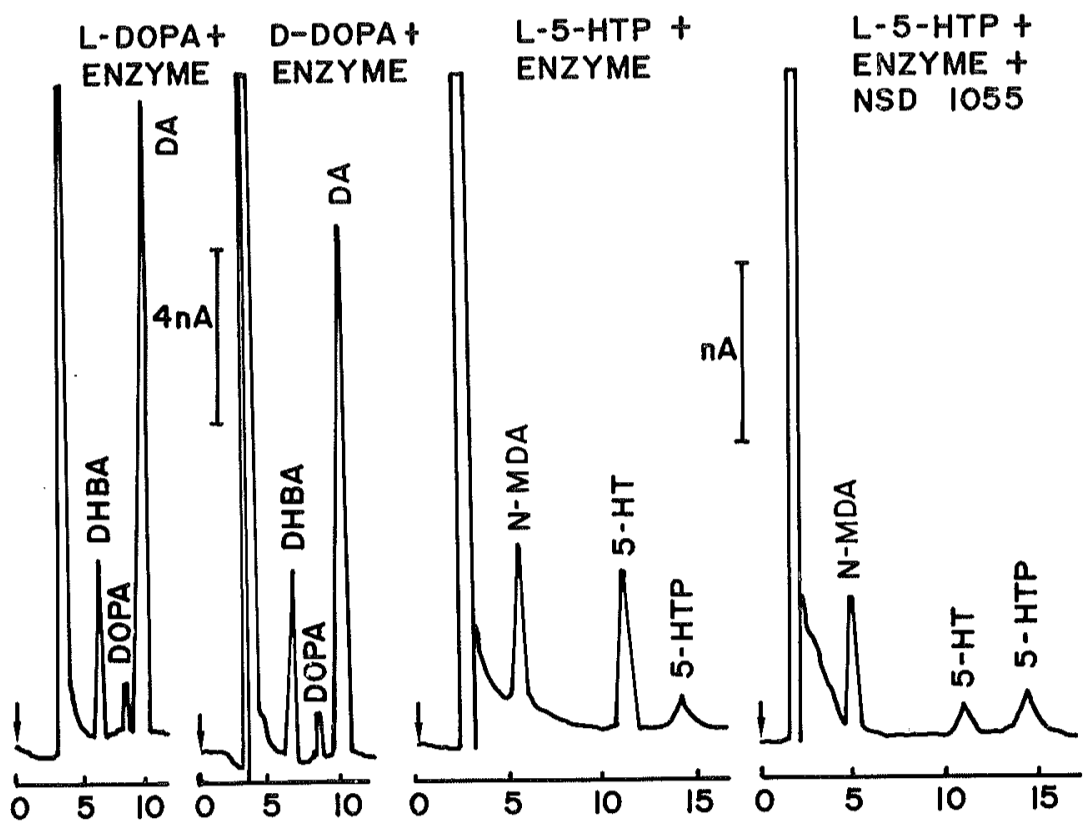

(B) Striato-nigral degeneration

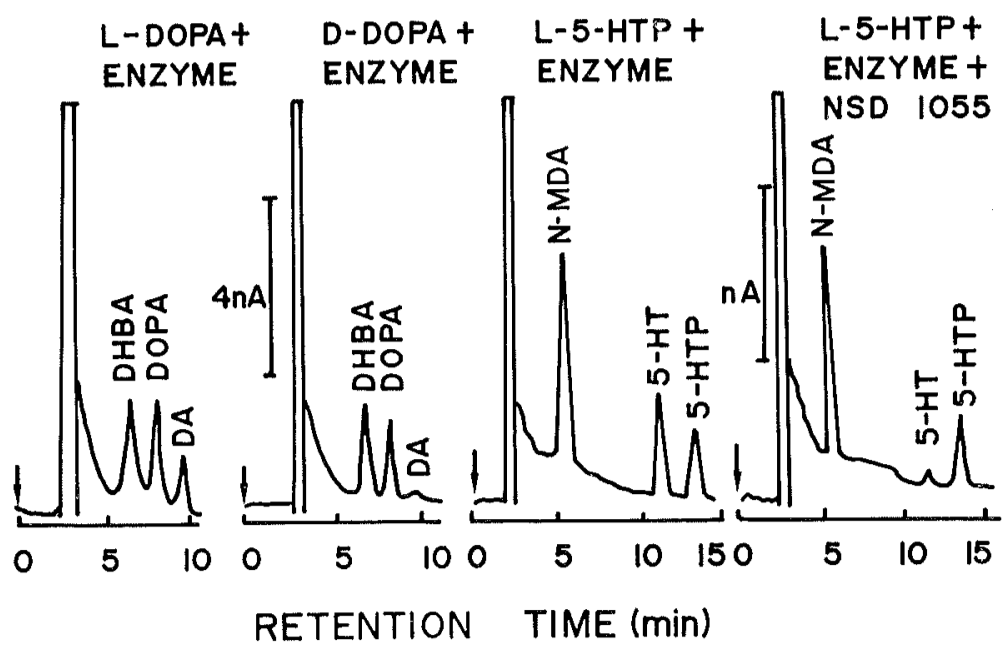

Fig. 1

receiving any drugs to affect the enzyme activity. The patients had not received L-DOPA at least 6 months before death.

For AADC assays the dissected area was minced finely with scissors, and a portion was removed and weighed for homogenization. The tissues were homogenized with $0.32 \mathrm{M}$ sucrose solution in a Potter glass homogenizer. All tissues were diluted 5-fold, except the caudate nucleus (3-20-fold dilution), hypothalamus (520-fold dilution), raphé nucleus (10-20-fold dilution) and mammillary body (10-fold dilution).

\section{Reagents}

L-DOPA, L-5-HTP, $N$-methyldopamine ( $N$-MDA), D-DOPA, and pargyline $\mathrm{HCl}$ were obtained 
from Sigma Chemical Co. (St. Louis, MO), pyridoxal phosphate was from Katayama Chemicals (Osaka), Amberlite CG-50 was from Rohm and Haas (Philadelphia, PA), EDTA was from Tokyo Kasei Co. (Tokyo), and 3,4-dihydroxybenzylamine $\mathrm{HBr}$ (DHBA) was a kind gift from Eizai Pharmaceutical Co. (Tokyo). All other chemicals were of analytical grade. Amberlite CG-50 (type 1, 100-200 mesh) was activated by cyclic washing with $2 \mathrm{M} \mathrm{HCl}, 2 \mathrm{M} \mathrm{NaOH}$, and finally with water, equilibrated with $1 \mathrm{M}$ potassium phosphate buffer, $\mathrm{pH} 6.5$, and stored in the same buffer.

\section{Methods}

L-DOPA decarboxylase activity was measured by the method of Nagatsu et al. (10). The incubation mixture (total volume $400 \mu \mathrm{l}$, final $\mathrm{pH}$ 7.2) contained $30 \mathrm{mM}$ sodium phosphate $(\mathrm{pH}$ 7.2), $0.3 \mathrm{mM}$ EDTA, $0.17 \mathrm{mM}$ ascorbic acid, $0.1 \mathrm{mM}$ pargyline $\mathrm{HCl}$ (a monoamine oxidase inhibitor), $0.01 \mathrm{mM}$ pyridoxal phosphate, 1.0 MM L-DOPA (or D-DOPA for the blank), and homogenate as enzyme. Incubation was done at $37^{\circ} \mathrm{C}$ for $20 \mathrm{~min}$ and the reaction was stopped by adding $80 \mu 1$ of $3 \mathrm{M}$ trichloroacetic acid. After $10 \mathrm{~min}, 1.9 \mathrm{ml}$ of water and $20 \mu \mathrm{l}$ of 0.01 $\mathrm{M} \mathrm{HCl}$ containing $62.5-250 \mathrm{pmol}$ of DHBA as an internal standard were added, and the mixture was centrifuged at $1,600 \mathrm{~g}$ for $10 \mathrm{~min}$. The supernatant was passed through a column (pack-

Fig. 1 High-performance liquid chromatographic analysis of L-DOPA decarboxylase and L-5-HTP decarboxylase activities. The conditions were as described under Materials and Methods. A: The standard incubation mixture contained $20 \mathrm{mg}$ of the control human caudate nucleus tissue for both the substrates (DOPA and 5-HTP). DOPA and 5-HTP were incubated at $37^{\circ} \mathrm{C}$, for 20 and $240 \mathrm{~min}$, respectively. One hundred and twenty-five picomoles of DHBA or $250 \mathrm{pmol}$ of $N$-MDA were added to each sample after incubation as an internal standard. L-DOPA decarboxylase and L-5-HTP decarboxylase activity was calculated to be $290 \mathrm{pmol} / \mathrm{min} / \mathrm{g}$ tissue and $32.4 \mathrm{pmol} / \mathrm{min} / \mathrm{g}$ tissue, respectively, from the above charts. B: The standard incubation mixture contained $8 \mathrm{mg}$ and $20 \mathrm{mg}$ of the caudate nucleus tissue from a patient with striato-nigral degeneration for the substrates, DOPA and 5-HTP, respectively. DOPA and $5-\mathrm{HTP}$ were incubated at $37^{\circ} \mathrm{C}$ for 20 and $180 \mathrm{~min}$, respectively. One hundred and twenty-five picomoles of DHBA or 250 pmol of $N$-MDA were added to each sample after incubation. L-DOPA decarboxylase and L-5-HTP decarboxylase activity was calculated to be $284.0 \mathrm{pmol} / \mathrm{min} / \mathrm{g}$ tissue and 16.2 $\mathrm{pmol} / \mathrm{min} / \mathrm{g}$ tissue, respectively, from the above charts. ed volume, $0.5 \mathrm{ml}$ ) of Amberlite CG-50-Na ${ }^{+}$ equilibrated with $0.1 \mathrm{M}$ ptoassium phosphate buffer at $\mathrm{pH}$ 6.5. The resin was washed with $4.5 \mathrm{ml}$ of the buffer twice and with $200 \mu 1$ of 1 $\mathrm{M} \mathrm{HCl}$. The adsorted DA was eluted with 0.7 $\mathrm{ml}$ of $1 \mathrm{M} \mathrm{HCl}$. Fifty to $200 \mu \mathrm{l}$ of the eluate were injected into the high-performance liquid chromatograph (Yanaco L-2000) with a Yanaco VMD-101 electrochenical detector and a 'Nucleosil' reversed phase column (particle size, 7 $\mu \mathrm{m} ; 25 \times 0.4 \mathrm{~cm}$ i.d.) (Yanaco, Kyoto, Japan). The carrier buffer for HPLC was $0.1 \mathrm{M}$ potassium phosphate buffer, pH 3.2, containing $0.5 \%$ acetonitrile, with a flow rate of $0.86 \mathrm{ml} / \mathrm{min}$. The peak height of the DA was measured and converted to pmol from the peak height of the DHBA added as an internal standard to each incubation mixture. The retention time under these conditions was: DHBA, $6.5 \mathrm{~min}$; DOPA, $8.5 \mathrm{~min}$; and DA, $10.0 \mathrm{~min}$.

L-5-HTP decarboxylase activity was measured by the method of Rahman et al. (11). The incubation mixture (total volume $400 \mu \mathrm{l}$, final $\mathrm{pH}$ 8.2) contained $30 \mathrm{mM}$ sodium phosphate buffer (pH 9.0), $0.1 \mathrm{mM}$ pargyline $\mathrm{HCl}, 0.01 \mathrm{mM}$ pyridoxal phosphate, $1.0 \mathrm{mM}$ L-5-HTP (or L-5-HTP plus $0.2 \mathrm{mM}$ NSD 1055, an AADC inhibitor, for the blank), and homogenate as enzyme. Incubation was carried out at $37^{\circ} \mathrm{C}$ for $120-240$ min and the reaction was stopped by adding 80 $\mu \mathrm{l}$ of trichloroacetic acid. After 10 min $1.9 \mathrm{ml}$ of water and $20 \mu \mathrm{l}$ of $0.01 \mathrm{M} \mathrm{HCl}$ containing $125-250$ pmol of $N$-MDA as an internal standard were added, and the mixture was passed through the same procedures as described above for L-DOPA decarboxylase, but the adsorbed 5HT was eluted with $1.4 \mathrm{ml}$ of $1 \mathrm{M} \mathrm{HCl}$ and the carrier buffer for HPLC was $0.2 \mathrm{M}$ citrate buffer, $\mathrm{pH} 2.2$, with a flow rate of $1.1 \mathrm{ml} / \mathrm{min}$. The peak height of the 5-HT was measured and converted to pmol from the peak height of the $N$-MDA added as an internal standard to each incubation mixture. The retention time under these conditions was: $N$-MDA, $5.0 \mathrm{~min}$; 5 -HT, $11.5 \mathrm{~min}$; and 5-HTP, $14.0 \mathrm{~min}$.

\section{RESULTS}

AADC activity with L-DOPA and L-5-HTP as substrates could be clearly demonstrated in almost all brain regions of controls and patients with extrapyramidal diseases.

The chromatograms in Fig. 1 show the elution pattern of L-DOPA decarboxylase and L-5-HTP decarboxylase in the caudate nucleus of a control and a patient with striato-nigral degenera- 
tion. Fig. 1A shows that in the control brain the blank value for DOPA decarboxylase activity was higher than in the brain of the patient with striato-nigral degeneration (Fig. 1B) due to a decrease of endogenous DA.

Activity of AADC with L-DOPA and L-5-HTP as substrates and the ratio of the activity in brain regions of controls and patients with extrapyramidal diseases are shown in Table 2. High variations in the activity of L-DOPA decartoxylase and L-5-HTP decarboxylase and in the ratio between the two types of activity were observed either in different brain regions or in different patients.

In the control brains DOPA decarboxylase activity was high in the hypothalamus, caudate nucleus, amygdala, and putamen. Cerebral cortex, reticular formation, raphé nucleus and cerebellar nucleus had low DOPA decarboxylase activity. L-5-HTP decarboxylase activity was also high in the hypothalamus, caudate nucleus, putamen, and amygdala.

The high ratio between DOPA decarboxylase and 5-HTP decarboxylase activity was observed in catecholaminergic regions such as amygdala, hypothalamus, caudate nucleus, and putamen.

In the putamen, patients with Parkinson's disease, Shy-Drager syndrome, and perioral dyskinesia had low DOPA decarboxylase activity in comparison with the controls. L-5-HTP decarboxylase activity in the putamen was not detectatle in a case of Shy-Drager syndrome and was also low in Parkinson's disease and perioral dyskinesia in comparison with the controls. The ratio of the two types of activity in the putamen as low in perioral dyskinesia and striato-nigral degeneration in comparison with the controls and Parkinson's patients.

The ratio of the two types of activity in the caudate nucleus was similar in the controls and striato-nigral degeneration but high in one case of Shy-Drager syndrome.

\section{DISCUSSION}

As reported by Sachs et al. (14) and by us (10), the present study also confirmed that activity of AADC with L-DOPA as substrate in human

Table 2 Aromatic L-Amino Acid Decarboxylase (AADC) Activity with L-DOPA and L-5-Hydroxytryptophan (5-HTP) as Substrates in Brain Regions of Controls and Parkinsonian Patients

\begin{tabular}{|c|c|c|c|c|c|c|}
\hline \multirow{3}{*}{\multicolumn{2}{|c|}{ Brain region }} & \multicolumn{4}{|c|}{ AADC Activity (mean $\pm \mathrm{SE}$ ) } & \multirow{3}{*}{$\begin{array}{l}\text { Ratio of activity } \\
\text { L-DOPA } \\
\text { L-5-HTP }\end{array}$} \\
\hline & & L-DOPA & as substrate & L-5HTP as & substrate & \\
\hline & & \multicolumn{4}{|c|}{$\mathrm{pmol} / \mathrm{min} / \mathrm{g}$ tissue } & \\
\hline \multicolumn{7}{|c|}{ A. Controls } \\
\hline & Caudate nucleus (4) & $226 \pm 65$ & {$[88-384]$} & $25.8 \pm 7.1$ & {$[10-40]$} & 8.8 \\
\hline & Putamen (4) & $184 \pm 31$ & {$[102-384]$} & $23.9 \pm 5.8$ & {$[15-40]$} & 7.7 \\
\hline & Substantia nigra (1) & - & & 7.5 & & - \\
\hline & Hypothalamus (3) & $685 \pm 275$ & {$[140-1,020]$} & $52.4 \pm 24.5$ & {$[4.2-83.6]$} & 13 \\
\hline & Amygdala (3) & $233 \pm 183$ & {$[50-600]$} & $9.5 \pm 6.7$ & {$[3-23]$} & 25 \\
\hline & Reticular formation (1) & 54.4 & & 3.3 & & 16 \\
\hline & Raphé nucleus (2) & 30.0 & {$[20,40]$} & 7.5 & {$[7.5,-]$} & 4 \\
\hline & Cerebral cortex (2) & 60.0 & {$[50,70]$} & 9.0 & {$[8,10]$} & 6.6 \\
\hline & Cerebellar nucleus (2) & 35.0 & {$[25,45]$} & 0.0 & {$[0.0,0.0]$} & - \\
\hline \multicolumn{7}{|c|}{ B. Parkinson's disease } \\
\hline & Putamen (4) & $111 \pm 4^{*}$ & {$[100-121]$} & $7.2 \pm 3.4^{*}$ & {$[0.8-17.4]$} & 15.4 \\
\hline & Amygdala (2) & 147 & {$[86.5,207]$} & 212 & {$[5.6,418]$} & 0.7 \\
\hline & Reticular formation (1) & 42.9 & & 1.2 & & 36 \\
\hline & Raphé nucleus (1) & 308 & & 63.8 & & 4.6 \\
\hline & Cerebellar cortex (2) & 124 & {$[98.1,149]$} & 125 & {$[27.7,223]$} & 1.0 \\
\hline \multicolumn{7}{|c|}{ C. Striato-nigral degeneration } \\
\hline & Caudate nucleus ( 2 ) & 389 & {$[495,284]$} & 58.1 & {$[100,16.2]$} & 6.7 \\
\hline & Putamen (1) & 339 & & 86.9 & & 3.9 \\
\hline & Mammillary body (1) & 71.4 & & 17.7 & & 4.0 \\
\hline \multicolumn{7}{|c|}{ D. Shy-Drager syndrome } \\
\hline & Caudate nucleus (1) & 114 & & 1.8 & & 63.0 \\
\hline & Putamen (1) & 8.1 & & 0.0 & & - \\
\hline \multirow[t]{3}{*}{ E. } & Perioral dyskinesia & & & & & \\
\hline & Putamen (1) & 16.2 & & 9.4 & & 1.7 \\
\hline & Mammillary body (1) & 0.0 & & 3.8 & & - \\
\hline
\end{tabular}

${ }^{*} P<0,05$ for difference between controls and Parkinson's disease. Numbers of samples are indicated in parentheses, and the individual activity in each patient in square brackets. 
brain, although present, was very low in comparison with rat brain and showed a wide spread of values.

AADC activity with L-5-HTP as substrate has been reported to be even lower than the activity with L-DOPA as substrate, or almost undetectable $(4,15)$. In this study, we have applied our highly sensitive HPLC-ED assay of 5-HTP decarboxylase activity (11) to human brain and we have succeeded for the first time in measuring the enzyme activity accurately in various human brain regions.

The distribution of L-5-HTP decarboxylase activity was nearly parallel with that of DOPA decarboxylase activity. However, the ratio between the activity with L-DOPA and that with L-5-HTP varied in various brain regions from controls and patients with extrapyramidal diseases.

Sachs et al. (14) reported that the DOPA decarboxylase activity in the hypothalamus of postmortem human brains was about $20 \mathrm{nmol} /$ $\mathrm{hr} / \mathrm{g}$ tissue. The control hypothalamus in this study had a mean DOPA decarboxylase activity of $40 \mathrm{nmol} / \mathrm{hr} / \mathrm{g}$ tissue. In the hypothalamus of control brains 5-HTP decarboxylase activity ranged from 0.2 to $5 \mathrm{nmol} / \mathrm{hr} / \mathrm{g}$ tissue, with a mean value of about $3 \mathrm{nmol} / \mathrm{hr} / \mathrm{g}$ tissue. Therefore, the ratio of AADC activity between DOPA and 5-HTP as substrates was about 13. Lloyd and Hornykiewicz (4) first detected 5-HTP activity in human putamen homogenate with DL-5HTP $\left[3-{ }^{14} \mathrm{C}\right]$ as substrate and they reported that the ratio of decarboxylation for DOPA to that of 5 -HTP was about 10 . This value is similar to our data (about 8 in the control putamen).

In various disease conditions, the enzyme activity towards the two substrates also found to vary. In this study, L-5-HTP decarboxylase activity was first measured in patients with Parkinson's disease, striato-nigral degeneration, Shy-Drager syndrome, and perioral dyskinesia. In Shy-Drager syndrome and perioral dyskinesia, AADC activity appeared to be decreased markedly in the putamen. Lloyd and Hornykiewicz first reported that the activity of L-DOPA decarboxylase was greatly reduced in the striatum of patients with Parkinson's disease (3). We also found low L-DOPA decarboxylase activity in the striatum of about two-thirds of the cases of Parkinson's disease, but the enzyme activity in about one-third of cases was found to be normal or even higher than normal (6-8). In the present study DOPA decarboxylase activity in the putamen of patients with Parkinson's disease was found to be about $50 \%$ of that of the con- trols. L-5-HTP decarboxylase activity in the striatum of patients with Parkinson's disease was also found to be reduced to about $30 \%$.

All of these observations on regional distribution of AADC activity with both L-DOPA and L-5-HTP as substrates in the brains from control patients and Parkinsonian patients tend to support the hypothesis that there may exist two different types of AADC with different substrate specificity for L-DOPA and L-5-HTP. However, this can only be proved by isolating different types of $\mathrm{AADC}$ from human brain.

Received for publication 31 July 1981

\section{REFERENCES}

1. Christenson T. G., Dairman W. and UdenFRIEND S. (1972) Preparation and properties of a homogeneous aromatic L-amino acid decarboxylase from hog kidney. Arch. Biochem. Biophys. 114, 356-367

2. Ehringer H. und Hornykiewicz O. (1960) Verteilung von Noradrenalin und Dopamin (3Hydroxytyramin) in Gehirn des Menschen und ihr Verhalten bei Erkrankungen des Extrapyramidalen Systems. Klin. Wochenschr. 24, 12361239

3. Lloyd K. and Hornykiewicz O. (1970) Parkinson's disease: activity of L-dopa decarboxylase in discrete brain regions. Science 170, 1212-1213

4. Lloyd K. and HoRnykiewicz O. (1972) Occurrence and distribution of aromatic $L$-amino acid (L-dopa) decarboxylase in the human brain. $J$. Neurochem. 19, 1549-1559

5. Lovenberg W., Weissbach H. and Udenfriend S. (1962) Aromatic L-amino acid decarboxylase. J. Biol. Chem. 237, 89-93

6. Nagatsu T., Kato T., Nagatsu I., Kondo, Y., INAGAKI S., IIZUKA $R$. and NaRABAYASHI $H$, (1979) Catecholaminerelated enzymes in the brain of patients with Parkinsonism and Wilson's disease. In Advances in Neurology (ed. Poirier L. J., Sourkes T. L. and Bedard P. J.) Raven Press, New York, pp. 283-292

7. Nagatsu T., Kato T., Numata T., Sano M. Nagatsu I., Kondo Y., Inagaki S., Iizuka R., Hori A, and NARAbayashi H. (1976) Phenylethanolamine- $N$-methyltransferase and other catecholamine enzymes in human brain from controls and Parkinsonian patients. Bull. Jap. Neurochem. Soc. 15, 68-71

8. Nagatsu T., Kato T., Numata (Sudo) Y., Ikuta K., Sano M., Nagatsu I., Kondo Y., InAGaki S., IIzUKa R., Hori A. and NarabaYASHI H. (1977) Phenylethanolamine- $N$-methyltransferase and other enzymes of catecholamine metabolism in human brains. Clin. Chim. Acta 75, 221-232

9. Nagatsu T., Yamaguchi T., Kato T., Sugi- 
moto T., Matsuura S., Akino M., Nagatsu I., IIZUKA R. and NARABAYASHI H. (1981) Biopterin in human brain and urine from controls and Parkinsonian patients: application of a new radioimmunoassay. Clin. Chim. Acta 109, 305311

10. Nagatsu T., Yamamoto T. and Kato T. (1979) A new and highly sensitive voltammetric assay for aromatic L-amino acid decarboxylase activity by high-performance liquid chromatography. Anal. Biochem. 100, 160-165

11. Rahman M. K., Nagatsu T. and Kato T. (1980) New and highly sensitive assay for L-5-hydroxytryptophan decarboxylase activity by high-performance liquid chromatography-voltammetry. J. Chromatogr. 221, 265-270

12. Rahman M. K., Nagatsu T, and Kato T. (1981) Aromatic L-amino acid decarboxylase activity in central and peripheral tissues and serum of rats with L-DOPA and L-5-hydroxytryptophan as substrates. Biochem. Pharmacol. 30, 645-649

13. Rahman M. K., Nagatsu T. and Kato T. (1981) Determination of aromatic L-amino acid decarboxylase in serum of various animals by highperformance liquid chromatography with electrochemical detection. Life Sci. 28, 485-492

14. Sachs W., Vogel. W. H., Nagatsu T., Lloyd K. G. and SANDler M. (1979) Is there DOPA decarboxylase in human brain? In Catecholamines: Basic and Clinical Frontiers (ed. UsDiN E., Kopin I. J. and Barchas J.) Pergamon Press, New York, pp. 127-131

15. Vogel W. H., Orfei V. and Century B. (1969) Activities of enzymes involved in the formation and destruction of biogenic amines in various areas of human brain. J. Pharmacol. Exp. Ther. 165, 196-203 